\title{
Ev Sahibi Olmak ve Eminevim Örneği
}

\section{Murat KUMBASAR ${ }^{*}$}

\section{Öz}

Dinimiz, ev sahibi olmayı asli ihtiyaçlardan saymaktadır. Bir evi olanlardan zekât almamaktadır. Mesken sahibi olmayı fıtri bir ihtiyaç olarak görmektedir. Eminevim organizasyonu bir "elbirliği" sistemi ve "teavün" yardımlaşma hareketidir. Kiracılığ liyettir.

Batılılar mücadeleyi öngördüğü halde biz Müslümanlar “yardımlaşmayı” esas alıyoruz. Rabbimizin beyan buyurduğu ve emrettiği şekliyle "İyilikte yardımlaşın” emrü fermanı bir şekilde tecelli etmektedir Bilindiği üzere, günümüzde yardımlaşmanın belki en güzel şekli "kurumsallaşarak" yapılan yardımlaşmadır.

Bazı hocalarımızın bir defaya mahsus olmak üzere banka kredisiyle ev alma izni de tutarlılı̆̆ını yitirmiş olup, "alternatif ev arayışları mutlaka değerlendirilmelidir” kanaatimizi efkârı umûmiyeye (kamuoyuna) iletmek isteriz.

Anahtar Kelimeler: İslam, Mesken, Kredi, Yardımlaşma, Faizsiz

\section{Having A House \& Eminevim Model}

\begin{abstract}
"To have a house" is a main necessity according to our religion. The ones who have only one house are accepted to be exempt about giving alms. Also it accepts the having a house as a natural necessity. Eminevim Organization is a cooperate and assistance system. It is business type that demands to finish the renting house system and support the people who want to buy a house.

Although western nationals foresee the struggle; we Muslims accept the assistance as the main. "Complete in goodness" is manifested as Allah stated

* Yrd. Doç. Dr., Atatürk Üniversitesi İlahiyat Fakültesi Temel İslam Bilimleri Bölümü Öğretim Üyesi (kumbasar@atauni.edu.tr)
\end{abstract}


and ordered. As it is known, maybe the most pleasant type of the assistance is "institutional assistance" nowadays.

The accepted decision stated some authorities about buying house with banking credit system only one has not been valid yet. That's why; we explain to public that people should consider the alternative financing method while buying the house.

Keywords: Islam, House, Credit, Solidarity, Interest-free

\section{Ev Sahibi Olmak ve Eminevim Örneği}

Bilindiği üzere insanın doğuştan getirdiği hakları beş temel olarak adlandırdı-

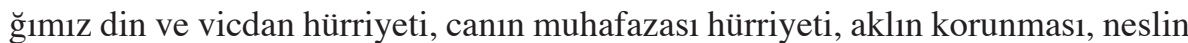
korunması ve malın muhafazası hakkı diye özetleyebileceğimiz, din-can-akıl-nesil-mal diye formüle edebileceğimiz bu temel haklarımız arasında mülkiyet edinme hakkımızın olduğunu özellikle belirtmemiz gerekir. Dinimiz, zekâtın alınmasını havaic-i asliyye şartına bağlamıştır. Bu şartın en önemli unsuru da bir mesken sahibi olmaktır. Ev sahibi olmak herkesin gönlünde yatan bir aslandır. Ticaret ehli, kamu görevlisi belki asgari ücretli ev sahibi olmayı hep düşünmüştür. Kimisi bu hedefine hemen ulaşmıș kimisi de ulaşamamıș ama bu düşüncesi daima var olmuştur. Hatta kendilerini sosyal devlet olan ülkeler, vatandaşlarının ev sahibi olmasını hizmetlerinin öncelikleri arasında görmüştür.

Mülk ve kâr kavramının hüsnü kabul gördüğü İslam ile mülkiyet ve kârın olmadığ 1 Komünizm sisteminin arasındaki en büyük farkta budur. Tabi burada Kapitalizmdeki mal ve kârın varlığını da İslam'la benzerlik olarak algılamamak gerekir. Çünkü onlara mal ve kârın tekelleşmesi söz konusudur. "Kâr"la birlikte haksız bir zulüm aracı olan "faiz"e yer vermiştir. Zenginler ve fakirler arasında uçurum mevcuttur. Kapitalizmin uygulandığı ülkelerde zengin daha zengin fakir daha fakir olmaya mahkûmdur. Buna mukabil komünist rejim, prensip olarak faize karşı olmakla beraber bunun yanında mülkiyet hakkına ve kâra da karşı çıkmak suretiyle her iki rejimde insan tabiatına aykırı düşmektedir. ${ }^{1}$

Uzun sözün kısası benim bir evim bulunmamaktadır. İfade edildiği üzere herkesin bir ev hayali bulunmaktadır. Benim de ev sahibi olma düşüncem olmuştur. Maaşımızdan tasarruf edelim, biriktirelim, önce peşinat sonra taksit ödeyelim şekilleri bize uymadı. Çünkü para biriktirme, tasarruf etme, peşinat hazırlama seçenekleri bir türlü beceremedik. Çünkü birkaç kere denememize rağmen başarılı olamadık. Dört çocuklu bir aileyiz; ikisi üniversite biri lise birisi de orta öğretimde okumakta. Aldığımız aylık ücretle ancak idare edebiliyoruz. Bütün bunları

1 Necmettin Erbakan, Davam, MGV Yayınları, Ankara 2014, s. 16 vd. 
söylerken her ay "ev" satın almak için az da olsa para ayırabileceğimizi ifade etmeliyim. Uzun araştırmalar yaptık. Önce inancımızla çelişen yani faizli banka kredisinin haram olduğunu gördük. Daha doğrusu mecburen maaşımızı bankadan almanın dışında bizim banka ile işimiz olmayacağını söylemeliyim. Finans kurumlarının sizin adınıza aldığı sonra size vadeli olarak sattığı evin de şüpheden ari olmaması bizi Eminevim organizasyonunu araştırmamıza sevk etti. Kadınların altın günü gibi değerlendirebileceğimiz sırası gelene evin alınması, peşinatı fazla verenlere daha erken, az verenlere veya hiç vermeyenlere daha geç bir sistemle ev sahibi yapıldığını gördük. Üç farklı sistemle ev sahibi olunabiliyor. Birincisi faiz ve vade farkı ödemeden her ay noter huzurunda yapılan bir çekilişle, ikincisi vade ortasi teslim yani taksitlerin faizsiz olduğu bu sistemde 60-80-100-120 aylık ödeme seçeneklerinin vade ortasına gelindiğinde ev teslimi, üçüncüsü peşinat ile erken ev teslimi. Görüldüğü üzere faizsiz ve vade farksız olması bu sistemin en önemli özelliğidir. Belki bizim tercihimizde en önemli faktör de burasıdır.

Bir de bu sisteme dâhil olurken alınan organizasyon ücretinin meşru mu gayrı meşru mu tartışmasını söyleyerek, dini yönden değerlendirmelerimize geçebiliriz. Organizasyon ücreti helaldir. Sistemi kurmuşlar, yürütüyorlar tabi ki maddi organizasyon ücreti almalılar. Çünkü hizmet yürümez aksar. Meselâ, seyahat organizasyonu yapan şirketler nasıl ki verdikleri hizmetten bir ücret alıyor iseler burada da verilen hizmetten dolayı ücret talebinin helal olduğu kanaatini taşımaktayım. Yalnız alınan organizasyon ücretini aylık oranlara göre artıyor veya eksiliyor. Yani 120'lik guruba girenler yüksek ücret öderken 60'llk guruba girenler daha az ücret ödemekteler. Burada bir ğabn (aldatma) olduğunu söylemek oldukça zor. Çünkü her şey şeffaf bir şekilde cereyan etmektedir. Yine de fazla ödememeden söz edilirse şunu söyleyebiliriz: Emin Şirketler Gurubu bünyesinde bir de "vakıf" bulunmakta. Hagev Vakfı, yardıma muhtaç yerli yabancı herkese ulaşarak bir büyük görev ifa etmektedir. Bu sonuca araştırmalarımız sonuca ulaştığımızı söyleyebiliriz.

Aşağıda açıklanacağı üzere "İvazlı hibe" olarak tarif edebileceğimiz bu uygulamanın meşru mu gayrı meşru mu olduğu hususunda fikir sahibi olunacağını belirtmememiz gerekir. Üyelerden her ay toplanan aidatlarla guruplara göre her birine bir ev alınması söz konusudur. Noter huzurundaki çekilişte ev almaya hak kazanan üyeye ne kadarlık bir eve girmişse (60-80-100-120-150) önce evi bulması isteniyor, bulunan ev eksperler marifetiyle satın alınarak ilgili kişi ev sahibi oluyor. Her ay gruptaki kişilerin ödediği taksit bir ev parası eder. Tapu çıkarılıyor elbette ki tapuya şerh düşürülüyor yani ipotek konuluyor. Taksitler bitiminde ödeme tamamlandığında ipotek çözülüyor ve evin tam ve gerçek sahibi olunuyor. Eve "satılamaz" şerhi konulmasıyla diğer müşterilerin hakkı korunmuş oluyor. Bilindiği üzere ipotek sistemi meşru bir sistemdir. Çünkü suiistimali ipotek sayesinde 
önleyebilirsiniz. Eminevim sistemi ile ev,arsa,iş yeri başta olmak üzere her türlü gayrimenkul alınabilir.

Eminevim sisteminin konut kredisi, mortgage(ipotek) ve diğer ev alma yöntemlerinden farkı nedir? Sorusunun cevabı şu şekilde verilebilir. Birçok fark sayılabilir ancak bunların en başında; faizsiz bir sistem olması, her bütçeye göre seçenekler sunması, Türkiye'nin her yerinden ev alınabilmesi, Kirada olanlar için yardım yapılması, ev alacak kişiye ödemelerinde kolaylıklar sağlamasını sıralayabiliriz. ${ }^{2}$

Ev geç çıktığında ev fiyatları o güne kadar artar, istediğim evi alamayabilirim düşüncesi ise Eminevim yetkilileri tarafından söyle cevaplandırılmaktadır:

- Eviniz geç çıktığında bugün düşündüğünüz evin o gün fiyatı büyük ihtimalle yükselecektir. Eminevim oluşan açığı kapatmak için iki farklı yöntem önermektedir. Bunlardan birincisi evinizi alana kadar size yapılacak yardımları ayrı bir hesapta biriktirmenizdir. Bu yöntemle o gün geldiğinde biriken yardımları ev almayı düşündüğünüz toplam rakamın üzerine ekleyip daha yüksek rakama düşündüğünüz evi alabilirsiniz. İkinci yöntem ise ilerleyen yıllarda gelirinizin de arttığını düşünürsek artan gelirinizin bir kısmıyla taksitlerinizi yükseltebilirsiniz yani almayı düşündüğünüz evin fiyatını arttırmış olursunuz.

- Eminevim sisteminde evin geç çıkması bir dezavantaj değildir. Evi geç çıkan müşterimiz o güne kadar kendinden önce evini alan kişilerden yardım aldığı için evini ucuza mal eder, taksitleri her ay belirli oranda azalır. Dolayısıyla evini erken alan ne kadar avantajlı ise geç alanda bir o kadar avantajlıdır. ${ }^{3}$

Ev çıkmadan kendisine kira yardımı yapıldı ğı halde ev çıktıktan kendisi diğer arkadaşlarına kira yardımında bulunuyor. Bir hususu önemine binaen ifade edeyim ki eğer biriken para iştirakçiye verilse ev veya otomobil alınmasa faize düşme tehlikesi söz konusu olabilir, hatta meşruluğu tartışılır hale gelirdi. Paradan para kazanmak tehlikesi gündeme gelirdi. Faizden ve vade farkından azade bu sistem, ev ve otomobil sahibi olmak isteyen dar gelirli ailelere bir "çıkış yolu" olma hüviyetini ihraz etmiştir. Halbuki Eminevim organizasyonu bir "elbirliği" sistemi ve "teavün" yardımlaşma hareketidir. Kiracılığı bitiren ve isteyen herkesi ev sahibi yapan bir faaliyettir.

Eminevim Şirketler Gurubu Başkanı Emin Üstün'ün 09.09.2015 tarihli çekiliş töreninin tanıtım filminde söylediği gibi "Batılılar mücadeleyi öngördüğü halde biz Müslümanlar "yardımlaşmayı" esas alıyoruz. Hakikaten Rabbimizin de beyan buyurduğu ve emrettiği şekliyle "İyilikte yardımlaşın” emrü fermanı bir şekil-

2 http://www.eminevim.com/merak_edilenler

3 http://www.eminevim.com/merak_edilenler 
de tecelli etmektedir. ${ }^{4}$ Bilindiği üzere günümüzde yardımlaşmanın belki en güzel şekli "kurumsallaşarak" yapılan yardımlaşmadır. İnsanlarımız arasında karşılıklı güven ortamı kalktığı veya azaldığ edebiliyoruz. Mesela normal şartlarda az gelirli kişilerin tasarruf imkanı dar olduğu için ne ev ne de araba sahibi olmaları neredeyse imkansız gibi gözükmektedir. Ancak "el birliğì" sistemi ile birbirimize yardım edebiliriz ki bu da bir nevi kurumsallaşmadır. İnsanlar artık birbirlerine borç dahi vermekten imtina ettiği bir zamanda faize ve bankaya bulaşmadan aralarında yardımlaşma suretiyle ev veya araba sahibi oluyorlarsa, bu sistemi kuranları tebrik etmek gerekir.

Ancak tespit edebildiğim konu içeriklerini madde madde eklemeye çalışacağım:

1- Bu tür organizeleri düzenlemelerinden dolay1 "Katılım ücreti" alınması/verilmesi caizdir.

2- Ortada olmayan bir malın (ev / araba vs) satışının geçerli olması için malın var olması ya da tesliminin mümkün olması gerekir. Zira olmayan bir şeyin satımı batıldır. Müşteri, alacağı evi daha en baştan (bina, kaçıncı katta, arsa vb) seçebilmeli, alışverişi onun üzerine yapmalıdır. Sonradan kura ile çıkacak mal, muallakta iken ödeme yapılamaz.

3- Alınan malın fiyatı en baştan bilinerek (kesin belirlenmiş bir fiyat üzerine) antlaşma yapılmalıdır.

4- Kura ile teslim antlaşmalı alışveriş sisteminde, Kuranın erken çıkması durumunda anlaşılan / belirlenmiş olan aylık ödeme taksit miktarı arttırılmaktadır ki (Kura çıkan kimse ise, grup üyelerine \%3,5 -üç buçuk- kira yardımı yapmaktadır. Bu şekilde ilk ay kura çıkıp ev alınan kimse ile son ay ev sahibi olan kimsenin enflasyondan kaynaklanan paranın değer kaybetmesinden etkilenmemesi sağlanma niyetiyle), bu caiz değildir.

5- Bu tür şirketler (genelde) Alışverişi üzerine anlaşılan (satın alınan) malın (ev / araba vs) kendisini ipotek ederler ki, satın alınan malın kendisinin ipotek edilmesi alışverişi fasid kılar, caiz değildir. Bu sebeple eğer illâ ki ipotek alacaksa, satın alınan maldan başka bir malı ipotek yapmaları gerekir ki, bunu da çok zor kabul etmektedirler.

Âişe (r.anhâ)'dan, şöyle nakledilmiştir:

"Peygamber (s.a.v.), Ebû Şahn adında bir Yahudî'den veresiye yiyecek satın ald ve demirden zirhın ona rehin verdi" ${ }^{5}$

4 Maide: $5 / 2$

5 Buhârî, Ebu Abdillah Muhammed b. İsmail, el-Camiu's-Sahih, Çağrı Yayınları, İstanbul 1992, İstikrâz, I, Bûyu,14. 
Katâde'nin, Enes (r.anh)'dan rivayeti ise şöyledir:

"Rasûlullah (s.a.v) Medîne'de bir Yahudi'nin yanına zırhını rehin bıraktı ve ondan âile fertleri için arpa satın aldı"

6- Organizasyondan çıkmak için” bunu alışverişin öncesinde konuşmak gerekir.

İmam Ebu Hanife ve İmam Şafi'ye göre, böyle bir şart (hıyaru'ş-şart = sonradan vazgeçebilirim) ancak 3 gün için geçerli olur. Daha fazla bir süre için geçerli değildir. Böyle bir şart koşulduğu takdirde sözleşme fasid olur.

Hanefi Mezhebi müctehidlerinden İmam Ebu Yusuf ve İmama Muhammed'e göre, ihtiyaç olması durumunda “hıyaru'ş-şart"kaydını koymak, aylarca sonrası için de caizdir. Fakat, böyle bir şartın / cayma süresinin mutlaka belli olması Malikîler dışındaki üç mezhebe göre- şarttır. ${ }^{7}$

7- Taraflar, işin başında yapılacak olan eşyanın tarif ve tavsifini yapıp (misâlen, yapılması planlanan evin aralarında ihtilaf çıkmayacak şekilde en ince ayrıntısına kadar özelliklerini, kullanılacak ürünün kalitesi vs. belirlenmeli) mâlum hale getirmek mecburiyetindedirler.

Masnu'un (siparişi verilen malın, misâlen ev), bedeli peşin veya veresiye olarak ödenebilir. Masnu', tarif ve tavsiyeye uygun olarak imal edilmemişse/yapılmamışsa, mustasnı' (işi yaptıran, siparişi veren, muşteri), onu kabul veya red hususunda muhayyer olmalıdır. İsterse kabul eder, isterse reddeder.

8- Gününde / vâdesinde ödenmeyen taksitlerden dolayı gecikme zammı adı altında normal taksitten fazla ödeme (faiz) alınır! ${ }^{8}$

Eminevim hakkında Mehmet Talu hocamızın görüşlerini paylaşmak isteriz:

"Eminevim"in "Çekilişli Sistem, Vade Ortası Teslim ve Peşinatlı Erken Teslim" şeklinde uyguladığı sistem: İvaz yani bağışlanan tarafa herhangi bir mükellefiyet yükleyen şart ile yapılan hibe'den, bir teavün yani karşılıklı bir yardımlaşmadan, dayanışmadan ibarettir. Ekseriyetle kadınlar arasında düzenlenen "altın günü’ de bu iki prensibe dayanmaktadır. ALLAH Teâlâ şöyle buyurdu:

“... Iyilik etmek ve takva yani ALLAH Teâlâ'nın yasaklarından sakınma üzerinde birbirinizle yardımlaşın. Günah işlemek ve düşmanlık üzerine yardımlaşmayın. ALLAH Teâlâ'dan korkun; çünkü hiç şüphe yok ki ALLAH Teâlâ'nın cezası çok çetindir, şiddetlidir."

6 el-Cassâs, Ebu Bekir Ahmed b. Ali er-Razi; Ahkamu'l Kur'an, Beyrut 2003, II/258.

7 Vehbe Zühaylî, el-Fıkhu'l-İslami ve Edilletühü, Daru'l-Fikir, Dımaşk 1989, IV/254-257.

8 http://www.islam-tr.com/forum/konu/eminevim-sistemi-caiz-mi_.8337/

9 Maide: $5 / 2$ 
Görüldüğü üzere ALLAH Teâlâ birr u takva üzere teavünü emretmektedir.

Bunun karz-ı hasen veya sarf ile alakası bulunmamaktadır. Çünkü uygulamada iştirakçi yani organizeye katılanlar fiilen ne borç vericidir, ne de borç alıcıdır. Alıcı ve satıcı da değildirler. Onlar ancak karşılıklı hibe ve yardım edici ve hibeyi, yardımı kabul edicidirler.

Konu ile ilgili kısa bir bilgi verirsek:

Bazı hibelerin birer ivaz şartıyla yapılması muteberdir. Binaenaleyh ivaz şartıyla mukayyed olan hibeler, sadakalar sahih ve şart muteberdir, şer'an caizdir. Bu ivaz gerek hakikaten bir bedel olsun ve gerek birlikte ikamet etmek, zulümde bulunmamak, boşamamak gibi hükmen bir bedel, bir ivaz olsun müsavidir.

Meselâ: Bir kimse, bir şahsa hitaben: Bana şu kadar para vermek veya benim şu kadar borcumu ödemek şartıyla şu evimi sana hibe ettim deyip o şahıs da bu şartı kabul ve ifa eylese hibe lâzım olmuş olur.

Şart veya mükellefiyeti de içine alabilen ivazlı hibe başlangıç itibariyle hibe ise de, sonuç itibariyle satımdan ibarettir, bu yüzden de câizdir. ${ }^{10}$

Nitekim Mecelle, Madde:855 de: "İvaz şartı ile olan hibe sahih ve şart muteberdir.” hükmü yer alır. Bundan sonra, konu şu iki misalle açıklanır.

İvazı, hakîkî olan bedele misal:

Meselâ, bir kimse şu mekûle ivaz vermek, yahut kendisinin malûmül-mikdar deynini edâ etmek şartıyla, birine bir şey hibe ettikde, mevhûbün leh ol şarta riayet eder ise, hibe lâzım olur, etmez ise vâhib dahi hibesinden rücû' edebilir.

İvazı, hükmî olan bedele misal:

Kezalik bir kimse ölünce kendisini beslemek şartıyla mülk akarını birine hibe ve teslim ettikte, mevhûbün leh şart-1 mezkûr üzere vahibi beslemeğe razı iken, vahib nâdim olup da hibesinden rucû' ile ol akarını istirdad edemez.

Bu metnin sadeleştirilmesi:

İvazı, hakîkî olan bedele misal:

Meselâ, bir kimse şu malûm ivaz vermek, yahut kendisinin miktarı malûm borcunu ödemek şartıyla, birine bir şey hibe ettiğinde, kendisine hibe yapılan şahıs o şarta riayet eder ise, yani mezkûr ivazı verir veya o borcu öderse hibe lâzım

10 Ömer Nasuhi Bilmen, Hukuk-1 İslamiyye ve Istılahatı Fıkhiyye Kamusu, Bilmen Yayınları, İstanbul 1985, IV/241; es-Serahsî, Ebû Bekr Şemsü'l-eimme Muhammed, el-Mebsût, Dârü'l-Ma'rife, Beyrut, 1406/1986, XII/75; İbnu'l-Hümam, Kemuliddin Muhammed b. Abdıl-Vahid, Fethu'l-Kadir alel-Hidaye, Darül Fikr, Beyrut ts., IX/49; Zeylaî, Tebyinü'l-Hakalk, 5/98; ibn Nüceym, el-Bahru'r-Raık, 7/292; İbn Abidin, 8/488; ez-Zühaylî, el-Fıkhu'lİslami, 5/29. 
olur, yani artık hibeden dönemez, vaz geçemez. Riayet etmez ise hibe eden de hibesinden dönebilir, vaz geçebilir.

İvazı, hükmî olan bedele misal:

Yine bir kimse ölünceye kadar kendisine bakmak şartıyla mülkü olan malını birine hibe ve teslim ettiğinde, kendisine hibe yapılan şahıs, mezkûr şart üzere hibe edeni bakmaya razı iken, hibe eden pişman olup da hibesinden dönmekle, vaz geçmekle o akarını geri alamaz.

Fakat hibe edilen şahıs, koşulan şarta riayet etmezse hibe eden, hibesinden vazgeçerek hibe ettiği șeyi geri alabilir. Yoksa şartı ifa etmeye icbar edilemez. Çünkü bu, teberru demektir. Teberrua ise icbar edilemez.

İvaz şartıyla hibede ivazin malûm olması şarttır. İvaz meçhul olursa, şart fâsid olur. Hibe fâsid olmaz. Çünkü hibe, fasid şart ile fâsid olmayan akidlerdendir.

İvazlı hibe'nin caiz olması şu vb. hadis-i şeriflere dayandırılmaktadır:

Abdullah b. Abbas (R.A.) dan rivayete göre: Bir bedevî Resûlullah (S.A.V.) efendimize bir hibede bulundu. Resûlullah (S.A.V.) efendimiz de kendisine, buna mukabil karşılı̆̆ını verdi ve:

"Râzı oldun mu?" diye sordu. Bedevî:

- Hayır, dedi; Resûlullah (S.A.V.) efendimiz bedeli artırdı ve:

"Râzı oldun mu?" diye sordu. Bedevî yine:

- Hayır, dedi; Resûlullah (S.A.V.) efendimiz bedeli yine artırdı ve:

"Râzı oldun mu?" diye sordu. Bedevî:

- Evet, dedi. Daha sonra Hz.Peygamber (S.A.V.) efendimiz:

"Vallahi Kureyş'den veya Ensâr'dan yahut Sekîf'ten olandan başka hiç bir kimseden hibe almamak içimden geçti." ${ }^{11}$ buyurdu.

Hz.Ömer (R.A.) de, yapılan bir hibeye, karşılık bekleyen kimse hakkında: Ya bağışladığı şey geri verilmelidir, ya da mukabil bir ıvaz ödenmelidir, demiştir. ${ }^{12}$

İvaz verilmesi halinde hibeden dönülemeyeceği: Abdullah b. Ömer (R.A.) den rivayet edilen Resûlullah (S.A.V.) efendimizin:

"Bir şeyi hibe eden kimse, kendisine ondan bir karşıllk verilmediği müddetçe, hibesini geri almaya en müstehak olandır." ${ }^{13}$ hadis-i şerifinde bildirilmektedir.

11 Ahmed b. Hanbel, el-Müsned, Mektebetu'l-İslamiyye, Beyrut ty., I/295; Abdurrezzâk, elMusannef, (Thk. Habîburrahmân el-A'zamî), el-Mektebetu'l-İslâmî, Beyrut 1983, IX/105.

12 Abdurrezzak, el-Musannef, IX/105.

13 el-Hâkim, Muhammed b. Abdillah en-Nesayburi, Müstedrek Ala's-Sahihayn (Thk. Muhammed Abdülkadir), Darü'l-Kütübi'l-İlmiyye, Beyrut 1990, II/52. 
Hz.Ömer (R.A.) şöyle demiştir: Bir kimseye, Allah yolunda savaşsin diye bir atı hibe etmistim. Atın yanında olan o zât, ata iyi bakmadı ve onu zayıflattı. Ben de zât bu atı ucuza satar diye düsünerek, onu o adamdan satın almayı istedim. Ve hibe ettiğim bu atı tekrar satın alabilir miyim diye Hz.Peygamber (S.A.V.) efendimize sordum. Hz.Peygamber (S.A.V.) efendimiz:

"Ĕ̆er o adam bu atı sana bir tek dirhem karşılığında verse de, artık sen o atı satın alma. Çünkü sadakasina dönen kimse, kusmuğuna dönen köpek gibidir." 14 buyurdu.

İvazlı hibe'nin zikredilen bu vb. hadis-i şeriflere dayandırılması, esasında bu usulle, hibenin iki taraflı bir akde dönüşmesinin değil; bir kısım ibadetlerin işlenmesini, sosyal yardımlaşmayı teşvik etme gibi gayelerin hedeflendiği söylenebilir. Böylece bağışta bulunulan kişiye dinî veya ahlâkî bir görev yükleyen, onu hayra ve ibadete yönlendiren veya ölünceye kadar bakma gibi insanî bir maksat taşıyan bağışlamalara da imkân verilmiş olmaktadır.

Fakihlerin çoğunun, ivazlı akitlere konu olmasını uygun görmediği gayrımuayyen ve gayrımalum bir mal ve hizmetin, hibe akdinde ivaz olmasına müsaade etmesi, en azından böyle bir şartı, fâsit; akdi ise sahih görmesi bundan kaynaklanir.

Hibede ivaz, akit sonrasında bağışlanan tarafından gönüllü olarak verildiğinde İvazlı hibe, akit esasında şart koşulan veya kararlaştırılan bir karşılık konumunda olduğunda ise İvaz şartlı hibe söz konusudur.

Birinci tür ivazlı muamele, birbirinden bağımsız iki ayrı hibe akdi olarak da görülebilir ve bu tür ivaz akdin mahiyetine tesir etmez. Hatta hibeye hibeyle karş1lık verme, verilen hediyeye hediye ile mukabele etme çerçevesinde düşünüldüğünden olumlu da karşılanır.

Ata b. Ebî Müslim Abdullah el-Horasanî (R.A.) den rivayete göre Resûlullah (S.A.V.) efendimiz:

"Birbirinizle musâfaha edin ki, kalplerdeki kin gitsin! Birbirinizle hediyeleşin ki birbirinize sevginiz artsin ve aradaki dïşmanlık yok olsun." 15

İvaz şartlı hibe ise Hanefîler'den Züfer dahil fakihlerin çoğunluğuna göre başlangıçtan itibaren satım hükmünde iken Hanefîler'in çoğunluğuna göre başlangıç

14 Buhârî, Ebu Abdillah Muhammed b. İsmail, el-Camiu's-Sahih, Çağrı Yayınları, İstanbul 1992, Hibe, 29, No: 925; Müslim, Ebu Hüseyin Müslim b. Haccac el-Kureyşi en-Nisaburi, Sahih-i Müslim, Çağrı Yayınları, İstanbul 1992, Hibe, 2.

15 Malik b. Enes, el-Muvatta, (Thk. Muhammed Fuad Abdülbaki), Darü'l-İhyai'l-Kütübi'lArabiye, Kahire, Hüsnü'l-Huluk, 4, No: 1731, 2/407; Buhârî, İstikraz, I, Büyu, 14; el-Cassâs, Ahkamu'l-Kur'an, II/258; Zühaylî, el-Fıkhu'l-İslami, IV/254-257. 
itibariyle hibe; sonuç itibariyle satım sayılır. Yapılan işlemin hibe veya satım sayılması bilhassa kabz öncesi akdin bağlayıcılık kazanması, şüf'a, ayıp veya görme muhayyerliği gibi hakların gündeme gelmesi yönüyle önem taşır. Ayrıca bu tür ivaz, akdi bir bakıma iki taraflı hale getirdiğinden bağışlayanın akdî sorumluluğuna ve rücû hakkına da olumsuz yönde tesir eder.

\section{Eminevim organizatördür}

Sistem incelendiğinde, uygulamada Eminevim; organize sözleşmesinde, fiilen vekâlet ve kefalet de bulunan belirli şartlar ve belli bir akit ile yüzlerce, hatta binlerce iştirakçiyi, katılımcıyı bir araya getiren organizatördür, satıcı değildir. Aldığı ücret, organize ücretidir, yani yaptıkları hizmet, iş karşılığında aldıkları bir ücret, bir komisyondur.

Bir malın veya hizmetin satımında aracı olunması karşılı̆̆ında alıcı veya satıcıdan yahut her ikisinden aralarında tespit edilen oranda ücret, komisyon alınmas1, tarafların aldatılması gibi İslam'ın yasakladığı bir durum söz konusu olmadıkça helaldir.

Eminevim, icabında biriken organize ücretini değerlendirmek veya iştirakçilere daha ucuza mal etmek maksadıyla ayrıca inşaat sektörüne girip ev vs. yaparsa, bunu iştirakçilere satamaz, satarsa organize veya emlak ücreti alamaz. Çünkü satıcının satış bedelinden başka bir ücret, mesela emlakçı veya organize ücreti alması caiz değildir.

Bu sebeple Eminevim'in bu gibi faaliyetlerini başka bir şirket adı altında yapması ve organizatör adıyla A veya B şirketinden; iştirakçilere satın aldığı gibi o şirketten satın alması gerekir.

Grupta evini teslim alan iştirakçilerin, normal taksitlerinden fazla ödedikleri miktarın, organize gereği kendilerinden sonra ev alacaklara bir yardım kabul edilmesi, kira olarak değerlendirilmemesi gerekir. Çünkü evini alan kişi, artık o evin sahibi olmuştur, ev sahibi kira ödemez. Ev sahiplerinin ödedikleri fazla miktar, organize gereği şart koşulan bir hibe, bir yardım olup kesinlikle borçlanma değildir. Binaenaleyh ortalıkta ne "ribal-fadl" ve ne de "riben-nesâ"” vardır.

İştirakçi paranın bir kısmını peşin öderken, bunu müşteri vasfıyla da borç veren vasfiyla da yapmıyor. Yukarıda izah edildiği gibi şartlı hibe edici vasfıyla yapıyor. Parayı alan yani Eminevim de organize sözleşmesi gereği almaktadır.

Taksitlerini dondurmayıp zamanında ödemeyen iştirakçilere, müeyyide ve yaptırım maksadıyla herhangi bir oranda gecikme cezası yansıtılması ivazlı hibe ve teavüne aykırıdır. Bunun yerine:

a- İştirakçi, evini eğer teslim almamışsa, ödemediği taksit kadar teslim tarihi ileri atılabilir, tıpkı öne alındığı gibi. 
b- İştirakçi, evini eğer teslim almışsa, ödemediği taksitlere, vaki tüfe miktarı hibesinde artırma şartı eklenebilir. Bu miktar da Eminevim'e değil; sadece o iştirakçinin dahil olduğu gruba ait olur.

Organizede, dinin temel prensiplerine aykırı olmayarak koşulan bir takım şartlar, meşrûdur. Çünkü şart veya mükellefiyeti de içine alabilen ivazlı hibe başlangıç itibariyle hibe ise de, sonuç itibariyle satımdan ibarettir, bu yüzden de câizdir."16

\section{Sonuç}

Yukarıdan beri izah edildiği üzere "havaici asliyye"den sayılan mesken yani ev, Dinimizce aslî ihtiyaç olarak görülmüş, zekâttan muaf tutulmuştur. Ev sahibi olmak, zengin olmakla eş değer görülmemelidir. Çünkü her ev sahibini zengin sayamayı. Sadece asli ihtiyaçlarından birine sahip olduğuna hükmederiz.

Sadede gelecek olursak, orta ve dar gelirli ailelerin ev sahibi olması neredeyse (faiz ve krediye düşmeyecekse) imkânsız gibidir. Çünkü gelir bellidir. O gelirle, ev sahibi olmak her yiğidin harcı değildir. Böyle olunca bu gelir guruplarının, ev sahibi olması için alternatif arayışında olması gayet tabiidir ve doğaldır. Onların da ev sahibi olma hakları vardır. Hep kiracı olmak, onların kaderi olmamalıdır. Bir çıkış yolu aranmalıdır. İnceleme ve araştırma neticesinde bizzat kendi yetkilileriyle görüşmeler, internet ortamında gazete vb. yayınların değerlendirilmesi sonucunda Eminevim Organizasyonundan bir ev sahibi olmayı daha önce beyan etmiştim. Kendimden misal verecek olursam emekli olsam dahi ulaşamayacağım eve, Eminevim sayesinde ulaşabileceğim kanaati hasıl oldu. Erzurum'da ev sahibi olma niyetiyle 150000 yüzellibin liralık evi,100 aylık guruba dahil olma suretiyle 51. ayda evimize kavuşmak üzere ( arada fazla yatırmasak bile) dört sene üç ay gibi bir sürede evimize ulaşmak gibi bir imkân sunulduğunu gördük. Aradaki çekilişlerde kur'a bize çıkarsa onu da bir nimet olarak göreceğimizi açıklamalıyım. Bu arada bizim dahil olduğumuz guruba 9735 lira organizasyon ücreti ödediğimizi de söylemeliyim. Yukarıda da beyan etmiştim bu organizasyon bedeli meşrudur ve hizmetin devamı için de belki elzemdir.

Şayet banka kredisi kullanılmış olsaydı (TOKİ vb) bizim ödediğimiz faiz, Eminevim organizasyon ücretinden kat be kat daha fazla olacak, manevi mes'uliyeti de yanında cabası olacaktı.

Bazı hocalarımızın bir defaya mahsus olmak üzere banka kredisiyle ev alma izni de böylece tutarlılığını yitirmiş olup, "alternatif arayışları mutlaka değerlendirilmelidir” kanaatimizi efkârı umûmiye’ye iletmek isteriz.

$16 \mathrm{http} / /$ www.islam-tr.com/forum/konu/eminevim-sistemi-hakkinda-genis-bilgi.31672/ 


\section{Kaynakça}

Kur'an-1 Kerim

Ahmed b. Hanbel, el-Müsned, Mektebetu'l-İslamiyye, Beyrut ty.

Abdurrezzâk, el-Musannef, (Thk. Habîburrahmân el-A'zamî), el-Mektebetu'l-İslâmî, Beyrut 1983.

Bilmen, Ömer Nasuhi, Hukuk-ı İslamiyye ve Istılahatı Fıkhiyye Kamusu, Bilmen Yayınları, İstanbul 1985.

Buhârî, Ebu Abdillah Muhammed b. İsmail, el-Camiu's-Sahih, Çağrı Yayınları, İstanbul 1992.

el-Cassâs, Ebu Bekir Ahmed b. Ali er-Razi, Ahkamu'l Kur'an, Beyrut 2003.

Erbakan, Necmettin, Davam, MGV Yayınları, Ankara 2014.

el-Hâkim, Muhammed b. Abdillah en-Nesayburi, Müstedrek Ala's-Sahihayn (Thk. Muhammed Abdülkadir), Darü'l-Kütübi'l-İlmiyye, Beyrut 1990.

İbnu'l-Hümam, Kemuliddin Muhammed b. Abdıl-Vahid, Fethu'l-Kadir alel-Hidaye, Darül Fikr, Beyrut ts.

Malik b. Enes, el-Muvatta, (Thk. Muhammed Fuad Abdülbaki), Darü'l-İhyai'1-Kütübi'1-Arabiye, Kahire.

Müslim, Ebu Hüseyin Müslim b. Haccac el-Kureyşi en-Nisaburi, Sahih-i Müslim, Çağrı Yayınları, İstanbul 1992.

es-Serahsî, Ebû Bekr Şemsü'l-eimme Muhammed, el-Mebsût, Dârü'l-Ma'rife, Beyrut, $1406 / 1986$.

Zühaylî, Vehbe, el-Fıkhu'l-İslami ve Edilletühü, Daru'l-Fikir, Dımaşk 1989.

http://www.eminevim.com/merak_edilenler

http://www.islam-tr.com/forum/konu/eminevim-sistemi-hakkinda-genis-bilgi.31672/

http://www.islam-tr.com/forum/konu/eminevim-sistemi-caiz-mi_.8337/ 